\title{
Chronic Oral Nicotine Normalizes Dopaminergic Function and Synaptic Plasticity in 1-Methyl-4-Phenyl-1,2,3,6- Tetrahydropyridine-Lesioned Primates
}

\author{
Maryka Quik, Li Chen, Neeraja Parameswaran, Xinmin Xie, J. William Langston, and Sarah E. McCallum \\ The Parkinson's Institute, Sunnyvale, California 94089
}

\begin{abstract}
Our recent studies show that chronic oral nicotine partially protects against striatal damage in 1-methyl-4-phenyl-1,2,3,6tetrahydropyridine (MPTP)-treated nonhuman primates. To identify the cellular changes associated with this protective action, we investigated the effects of nicotine treatment on stimulus-evoked dopamine release, dopamine turnover, and synaptic plasticity in striatum from lesioned and unlesioned animals. Monkeys were chronically (6 months) treated with nicotine in the drinking water and subsequently lesioned with the dopaminergic neurotoxin MPTP (6 months) while nicotine was continued. Nigrostriatal damage increased nicotinic acetylcholine receptor (nAChR)-mediated fractional dopamine release from residual terminals, primarily through changes in $\alpha 3^{\star} / \alpha 6^{\star}$ nAChRs. In contrast, fractional receptor-evoked dopamine release was similar to control in unlesioned and lesioned animals with chronic oral nicotine. Long-term nicotine administration also attenuated the enhanced $\mathrm{K}^{+}$-evoked fractional dopamine release from synaptosomes of MPTP-lesioned animals, suggesting that nicotine treatment had a generalized effect on dopaminergic function. This premise was further supported by experiments showing that nicotine dosing decreased the elevated dopamine turnover that occurs after nigrostriatal damage. We next investigated changes in synaptic plasticity with lesioning and nicotine treatment. Nicotine treatment alone enhanced synaptic plasticity by lowering the threshold for long-term depression (LTD) in the corticostriatal pathway. MPTP lesioning led to a loss of LTD, a measure of short-term synaptic plasticity. In contrast, LTD was preserved in nicotine-treated lesioned animals. Thus, the present data show that the disruptions in striatal dopaminergic function after nigrostriatal damage were attenuated with chronic nicotine administration. These cellular alterations may underlie the ability of nicotine to maintain/restore normal function with nigrostriatal damage.
\end{abstract}

Key words: nicotine; Parkinson's disease; nonhuman primates; nicotinic; dopamine; MPTP

\section{Introduction}

Epidemiological studies have repeatedly shown that smoking is associated with $\sim 50 \%$ decreased incidence of Parkinson's disease, a neurological disorder characterized by a loss of dopaminergic neurons in the nigrostriatal pathway (Morens et al., 1995; Allam et al., 2004; Olanow, 2004; Samii et al., 2004; Schapira, 2004). Although the active component in cigarette smoke is not yet known, accumulating evidence points to a role for nicotine as a contributor to this apparent neuroprotective effect (O'Neill et al., 2002; Quik, 2004). Support for this possibility stems from studies showing that exposure of cultured cells to nicotine attenuates cellular degeneration (Jin et al., 2004; Papke et al., 2004; Zhou et al., 2004), including damage induced by neurotoxins that selectively destroy dopamine neurons (Jeyarasasingam et al., 2002). In vivo studies also indicate that nicotine protects against nigrostriatal damage, although inconsistencies have been ob-

Received Jan. 17, 2006; revised March 26, 2006; accepted March 27, 2006

This work was supported by National Institutes of Health Grants ES012077, NS42091, and NS47162 and the Michael J. Fox Foundation.

Correspondence should be addressed to Maryka Quik, The Parkinson's Institute, 1170 Morse Avenue, Sunnyvale, CA 94089. E-mail: mquik@thepi.org.

DOI:10.1523/JNEUROSCI.0215-06.2006

Copyright $\odot 2006$ Society for Neuroscience $\quad$ 0270-6474/06/264681-09\$15.00/0 served in rodent models that may relate to the specific experimental paradigms used, species, or other factors (Janson et al., 1992; Hadjiconstantinou et al., 1994; Costa et al., 2001; Ryan et al., 2001; O’Neill et al., 2002; Parain et al., 2003; Quik, 2004). To more closely resemble the human condition, nonhuman primates were chronically administered nicotine in the drinking water and subsequently lesioned with several small doses of the dopaminergic neurotoxin 1-methyl-4-phenyl-1,2,3,6-tetrahydropyridine (MPTP) to induce slow nigrostriatal damage (Quik et al., 2005b). Nicotine treatment led to a partial return of tyrosine hydroxylase, the dopamine transporter, vesicular monoamine transporter, dopamine levels, and nicotinic acetylcholine receptors ( $\mathrm{nAChRs}$ ) in striatum of lesioned primates compared with lesioned animals not receiving nicotine (Quik et al., 2005b). These data demonstrate that nicotine dosing improves biochemical/anatomical markers of striatal dopaminergic nerve terminal integrity in lesioned monkeys compared with animals not receiving nicotine.

The present experiments were done to determine the functional consequences of chronic nicotine exposure on nigrostriatal damage at the cellular level. To approach this, we investigated the effect of nicotine administration on dopamine release and turnover in the striatum of unlesioned and lesioned animals treated 
with and without nicotine. These measures were selected because previous work had shown that nigrostriatal damage increased both dopamine turnover (Hornykiewicz, 1998, 2001) and evoked dopamine release from residual dopaminergic terminals (Zigmond et al., 1984, 1990; Zigmond, 1997; McCallum et al., 2006a). Moreover nicotine administration is well known to modulate nAChR function, including evoked dopamine release from striatum, both after acute and chronic exposure (Buisson and Bertrand, 2002; Gentry and Lukas, 2002; Dajas-Bailador and Wonnacott, 2004; Wonnacott et al., 2005).

To further elucidate the mechanism involved in this phenomenon, we investigated the effect of nicotine treatment on longterm depression (LTD) in corticostriatal slices from unlesioned and MPTP-lesioned primates. Previous work had shown that synaptic plasticity, as measured using LTD, is severely impaired after dopaminergic denervation in rodents (Calabresi et al., 1992a,b; Centonze et al., 1999, 2001). In the present study, we tested whether nicotine administration prevented this loss of plasticity in corticostriatal slices from MPTP-lesioned primates.

\section{Materials and Methods}

Animals. Adult female squirrel monkeys (Saimiri sciureus) were purchased either from Osage Research Primates (Osage Beach, MO) or the University of South Alabama (Mobile, AL). Animals were housed separately in a room with a 13/11 h light/dark cycle and were fed once daily with ad libitum access to water. A standard 4 week quarantine period was initiated on arrival. Before treatment, the monkeys were allowed to acclimatize to the home environment for $\geq 1$ month period. Animals were then randomly assigned to one of four treatment groups: control $(n=7)$, nicotine-treated ( $n=6)$, MPTP-treated $(n=7)$, or nicotine plus MPTPtreated $(n=6)$. All monkeys were given saccharin ( $1 \%$ solution) in the drinking water for a 2 week period. Animals in the nicotine treatment group were subsequently given ascending doses of nicotine in the drinking water, beginning with $25 \mu \mathrm{g} / \mathrm{ml}$ for 1 week, $50 \mu \mathrm{g} / \mathrm{ml}$ for 1 week, and increasing by $50 \mu \mathrm{g}$ increments/week over $\sim 3-4$ months up to a final concentration of $650 \mu \mathrm{g} / \mathrm{ml}$ (Quik et al., 2005b). The nicotine/saccharin solution was also added to food pellets that were given once daily. After 6 months of nicotine treatment, monkeys were given three doses of MPTP $(1.5 \mathrm{mg} / \mathrm{kg}$, s.c.) over a 6 month period at 2 month intervals with nicotine treatment continued until $24 \mathrm{~h}$ before death. The animals were killed according to the recommendations of the Panel on Euthanasia of the American Veterinary Medical Association. They were first injected intraperitoneally with euthanasia solution $(390 \mathrm{mg} / \mathrm{ml}$ sodium pentobarbital and $50 \mathrm{mg} / \mathrm{ml}$ phenytoin sodium), followed by $2.2 \mathrm{ml} / \mathrm{kg}$ (i.v.) of the same solution. All procedures conform to the National Institutes of Health Guide for the Care and Use of Laboratory Animals and were approved by the Institutional Animal Care and Use Committee.

Tissue preparation. The brain was rapidly removed and sectioned along the midline, and tissue was prepared as follows. One-half was placed in a squirrel monkey Plexiglas brain mold and sliced into 6-mm-thick sections, which were placed on glass slides and quickly frozen in isopentane on dry ice for autoradiographic studies. The mesencephalon containing the substantia nigra was dissected from the other one-half and fixed for tyrosine hydroxylase cell counts, while the remainder was sliced into 2 $\mathrm{mm}$ sections using the brain block. The caudate and putamen were dissected from the anterior slices (A15-A13) for measurement of dopamine and metabolite levels, dopamine uptake, and dopamine release, while the slice at level A13-A12 was used for electrophysiological recording.

Dopamine transporter autoradiography. Binding of $\left(3 \beta-\left(4-9^{125} \mathrm{I}\right)\right.$ iodophenyl)tropane-2 $\beta$-carboxylic acid isopropyl ester ( ${ }^{125}$ I-RTI-121) $(2200 \mathrm{Ci} / \mathrm{mmol}$; PerkinElmer, Wellesley, MA) was done to identify the dopamine transporter. Striatal sections were preincubated for $15 \mathrm{~min}$ two times in $50 \mathrm{~mm}$ Tris buffer, $\mathrm{pH}$ 7.4, plus $120 \mathrm{~mm} \mathrm{NaCl}$ and $5 \mathrm{~mm} \mathrm{KCl}$. This was followed by a $2 \mathrm{~h}$ incubation with $50 \mathrm{pm}{ }^{125} \mathrm{I}$-RTI- 121 in the same buffer also containing $0.025 \%$ bovine serum albumin and $1 \mu \mathrm{M}$ fluoxetine. To terminate binding, sections were washed for $15 \mathrm{~min}$ four times in ice-cold buffer and once in ice-cold deionized $\mathrm{H}_{2} \mathrm{O}$ for $10 \mathrm{~s}$. Slides were air-dried and exposed to Kodak MR film (Amersham Biosciences, Piscataway, NJ) for $\sim 3 \mathrm{~d}$. Nonspecific binding, determined in the presence of nomifensine (100 $\mu \mathrm{M})$, a dopamine uptake inhibitor, was similar to the film blank.

$\left[{ }^{3} \mathrm{H}\right]$ Dopamine release. Preparation of striatal synaptosomes and measurement of dopamine release was performed as described previously (McCallum et al., 2005). Striatal regions ( $\sim 15 \mathrm{mg}$ wet weight) were homogenized in $2 \mathrm{ml}$ of cold $0.32 \mathrm{~m}$ sucrose, $5 \mathrm{~mm}$ HEPES buffer, $\mathrm{pH} 7.5$, followed by centrifugation at $12,000 \times g$ for $20 \mathrm{~min}$. Pellets $(250 \mu \mathrm{g}$ of tissue) were resuspended in $0.8 \mathrm{ml}$ of uptake buffer $(128 \mathrm{~mm} \mathrm{NaCl}, 2.4$ mм KCl, $3.2 \mathrm{~mm} \mathrm{CaCl}_{2}, 1.2 \mathrm{~mm} \mathrm{KH}_{2} \mathrm{PO}_{4}, 1.2 \mathrm{~mm} \mathrm{MgSO}_{4}, 25 \mathrm{~mm}$ HEPES, $\mathrm{pH} 7.5,10 \mathrm{~mm}$ glucose, $1 \mathrm{~mm}$ ascorbic acid, and $0.01 \mathrm{~mm}$ pargyline). After $10 \mathrm{~min}$ incubation at $37^{\circ} \mathrm{C},\left[{ }^{3} \mathrm{H}\right]$ dopamine $\left(0.5 \mu \mathrm{Ci}\right.$ of $\left[{ }^{3} \mathrm{H}\right]$ dopamine for a final dopamine concentration of $100 \mathrm{~nm}$; $30-60 \mathrm{Ci} / \mathrm{mmol}$; PerkinElmer) was added, and incubation continued for $5 \mathrm{~min}$. An $80 \mu \mathrm{l}$ synaptosomal aliquot $(\sim 0.5-2 \mathrm{mg}$ tissue) was then placed onto $5-\mathrm{mm}$ diameter A/E glass-fiber filters. The synaptosomes were first perfused ( 1 $\mathrm{ml} / \mathrm{min}$ ) with uptake buffer containing $0.1 \%$ bovine serum albumin and $10 \mu \mathrm{M}$ nomifensine for $10 \mathrm{~min}$. Stimulated release from synaptosomes was initiated by an $18 \mathrm{~s}$ exposure to nicotine $(0.03-30 \mu \mathrm{M})$ or $20 \mathrm{~mm} \mathrm{~K}^{+}$. In some cases, the synaptosomes were preexposed to $50 \mathrm{~nm}$ $\alpha$-conotoxinMII (Tocris Cookson, Ellisville, MO) for 3 min before nicotine application. Fifteen $18 \mathrm{~s}$ fractions were collected, including fractions of basal release before and after stimulated release. Radioactivity was determined by liquid scintillation counting.

Dopamine and its metabolites. Approximately $5 \mathrm{mg}$ of tissue (each) was dissected from the medial and lateral caudate, and the dorsal and ventral putamen. Dopamine and its metabolites homovanillic acid (HVA) and dihydroxyphenylacetic acid (DOPAC) were extracted into $250 \mu$ l of $0.4 \mathrm{~N}$ perchloric acid. Catecholamines were determined using high-pressure liquid chromatography coupled to electrochemical detection (Quik and Di Monte, 2001).

Electrophysiology. After dissection, the $2 \mathrm{~mm}$ coronal monkey brain slice at level A13-A12 was bisected at the level of the internal capsule, and the portion containing the putamen was quickly placed in ice-cold, oxygenated buffer containing the following (in $\mathrm{mm}$ ): 248 sucrose, $1.5 \mathrm{KCl}$, $6.0 \mathrm{MgSO}_{4}, 1.0 \mathrm{CaCl}_{2}, 1.25 \mathrm{NaH}_{2} \mathrm{PO}_{4}, 26 \mathrm{NaHCO}_{3}$, and 11 glucose, $\mathrm{pH}$ 7.4. It was then cut into $300-350 \mu \mathrm{m}$ slices, using a vibratome in a plane to include cortex and putamen such that the corticostriatal connections between these two regions was maintained (Chen et al., 2006). The slices were incubated at room temperature for $\geq 1 \mathrm{~h}$ in oxygenated artificial CSF (ACSF), pH 7.4, containing the following (in mM): $124 \mathrm{NaCl}, 2.5$ $\mathrm{KCl}, 1.5 \mathrm{MgSO}_{4}, 2.0 \mathrm{CaCl}_{2}, 1.25 \mathrm{NaH}_{2} \mathrm{PO}_{4}, 26 \mathrm{NaHCO}_{3}$, and 11 glucose. A slice was transferred to the recording chamber and perfused with ACSF at $35^{\circ} \mathrm{C}$. Extracellular striatal field potentials were then recorded from the dorsal putamen as described previously (Chen et al., 2006) by bipolar stimulation $(0.1 \mathrm{~Hz} ; 100 \mu \mathrm{s} ; 6-8 \mathrm{~V})$ of the cerebral cortex or white matter between the cortex and putamen. Synaptic plasticity was determined by comparing average peak amplitude or slope of the striatal field potentials before and after high-frequency stimulation (HFS) $(100 \mathrm{~Hz} ; 100 \mu \mathrm{s} ; 14 \mathrm{~V}$ pulses). The quantitative data are expressed as a percentage of baseline, which represents the average amplitude of evoked field potentials, recorded after stabilization of the response 10-20 min before tetanic HFS.

Data analyses. $\left[{ }^{3} \mathrm{H}\right]$ Dopamine release was quantitated as previously described (McCallum et al., 2005). $R_{\max }$ and $\mathrm{EC}_{50}$ values were obtained from dose-response curves by fitting data to a nonlinear regression equation in SigmaPlot 2001 for Windows (SPSS, Chicago, IL). Fractional release was determined by dividing release for a particular sample by the dopamine transporter value to obtain a measure of release from residual dopaminergic terminals as reported previously (Snyder et al., 1990).

Statistical analyses were done using one- or two-way ANOVA followed by either Newman-Keuls or Bonferroni's post hoc test, respectively, using GraphPad Prism (San Diego, CA). All values are expressed as the mean \pm SEM of the indicated number of animals. A level of $p<0.05$ was considered significant. 
Table 1. Effect of nicotine and/or MPTP treatments on the striatal dopamine transporter

\begin{tabular}{llll}
\hline Striatal region & Treatment group & Number of animals & DAT (nCi/mg tissue) \\
\hline Medial caudate & Control & 7 & $35.3 \pm 1.6$ \\
& Nicotine $^{a}$ & 6 & $41.8 \pm 3.9$ \\
& MPTP & 7 & $21.9 \pm 2.9^{*}$ \\
Lateral caudate & Nicotine + MPTP & 6 & $25.8 \pm 3.4^{*}$ \\
& Control & 7 & $32.8 \pm 0.7$ \\
& Nicotine & 6 & $34.7 \pm 2.7$ \\
Ventral putamen & MPTP & 7 & $8.5 \pm 1.2^{*}$ \\
& Nicotine + MPTP & 6 & $13.6 \pm 3.2^{*}$ \\
& Control & 7 & $30.2 \pm 1.6$ \\
& Nicotine & 6 & $34.3 \pm 1.6$ \\
& MPTP & 7 & $17.7 \pm 2.5^{*}$ \\
Dorsal putamen & Nicotine + MPTP & 6 & $23.2 \pm 3.1^{*}$ \\
& Control & 7 & $33.5 \pm 1.1$ \\
& Nicotine & 5 & $34.5 \pm 1.4$ \\
& MPTP & 7 & $7.2 \pm 1.2^{*}$ \\
& Nicotine + MPTP & 6 & $12.4 \pm 3.0^{*}$
\end{tabular}

Monkeys were chronically administered nicotine in the drinking water and subsequently administered MPTP as described in Materials and Methods. Dopamine transporter autoradiography was done on striatal sections using ${ }^{125}$ I-RTI-121. DAT, Dopamine transporter. Significance of difference from control, ${ }^{*} p<0.001$.

${ }^{a}$ Nicotine values from McCallum et al. (2006b) for comparison with the other groups. The results were analyzed using a two-way ANOVA followed by Bonferroni's post hoc test.

\section{Results}

\section{Animal model}

For these studies, we provided nicotine to the monkeys in the drinking water, as this approach has the advantage that administration is pulsatile because animals drink sporadically throughout the day and yet chronic because treatment is provided over many months. As previously reported, this nicotine-dosing regimen resulted in plasma nicotine levels of $12.6 \pm 1.3 \mathrm{ng} / \mathrm{ml}(n=$ $12)$ and cotinine levels of $370 \pm 47 \mathrm{ng} / \mathrm{ml}(n=12)$, which are within the range of those in the plasma of smokers (Quik et al., 2005b). The chronic nicotine treatment was well tolerated; the animals appeared well on physical examination, and there were no significant differences in body weight or fluid intake among the groups (Quik et al., 2005b). The animals' activity was also measured using a computerized activity monitor system (Togasaki et al., 2005) with no differences in total daily activity among the four treatment groups (Quik et al., 2005b).

Low-dose MPTP $(1.5 \mathrm{mg} / \mathrm{kg})$ was administered subcutaneously three times at 2 month intervals to generate a relatively slow prolonged lesion. We used dopamine transporter autoradiography ( $\left.{ }^{125} \mathrm{I}-\mathrm{RTI}-121\right)$ as an index of dopaminergic damage, because this measure may reflect functional transporter sites at the terminal (Quik et al., 2001). MPTP treatment led to significant 40$80 \%$ decreases in dopamine transporter binding in the different striatal regions (Table 1). Two-way ANOVA yielded an overall significant main effect of MPTP lesioning $(p<0.001)$ in every region, consistent with previously reported measurements of striatal dopamine transporter using Western blots (Quik et al., $2005 \mathrm{~b})$. There was also a significant main effect of nicotine dosing $(p<0.05)$ in each striatal region, with no significant interaction between MPTP and nicotine treatment.

\section{Nicotine treatment normalizes MPTP-induced increases in fractional $\mathrm{nAChR}$-evoked dopamine release in striatum}

Experiments were next done to determine the effect of chronic nicotine in the drinking water on $\mathrm{nAChR}$-evoked dopamine release from striatal synaptosomes of unlesioned and lesioned monkeys (Table 2). Because MPTP treatment resulted in significant nigrostriatal damage or loss of dopamine terminals as re-
Table 2. Effect of nicotine and/or MPTP treatments on evoked dopamine release levels

\begin{tabular}{|c|c|c|c|c|}
\hline \multirow[b]{2}{*}{ Striatal region } & \multirow[b]{2}{*}{ Treatment group } & \multicolumn{3}{|c|}{$\begin{array}{l}\text { Maximal nAChR-mediated dopamine release } \\
\text { (cpm/mg protein) }\end{array}$} \\
\hline & & Total & $\alpha 4^{*}$ & $\alpha 6^{*}$ \\
\hline \multirow[t]{4}{*}{ Medial caudate } & Control & $6769 \pm 1083$ & $1974 \pm 306$ & $4825 \pm 799$ \\
\hline & Nicotine & $7001 \pm 796$ & $2845 \pm 102$ & $5021 \pm 698$ \\
\hline & MPTP & $7344 \pm 1100$ & $1834 \pm 320$ & $5555 \pm 849$ \\
\hline & MPTP + nicotine & $5941 \pm 493$ & $2240 \pm 208$ & $3876 \pm 366$ \\
\hline \multirow[t]{4}{*}{ Lateral caudate } & Control & $5024 \pm 992$ & $1497 \pm 306$ & $3681 \pm 709$ \\
\hline & Nicotine & $4522 \pm 1305$ & $1811 \pm 443$ & $2756 \pm 624$ \\
\hline & MPTP & $2826 \pm 575$ & $574 \pm 191$ & $2305 \pm 408$ \\
\hline & MPTP + nicotine & $2383 \pm 467$ & $863 \pm 220$ & $1594 \pm 340$ \\
\hline \multirow[t]{4}{*}{ Ventral putamen } & Control & $7287 \pm 602$ & $1675 \pm 200$ & $5636 \pm 459$ \\
\hline & Nicotine & $3820 \pm 862$ & $1331 \pm 150$ & $3182 \pm 703$ \\
\hline & MPTP & $8373 \pm 1218$ & $2839 \pm 429$ & $6127 \pm 858$ \\
\hline & MPTP + nicotine & $6102 \pm 818$ & $1996 \pm 258$ & $4015 \pm 622$ \\
\hline \multirow[t]{4}{*}{ Dorsal putamen } & Control & $3721 \pm 394$ & $877 \pm 197$ & $3010 \pm 238$ \\
\hline & Nicotine & $3115 \pm 518$ & $1062 \pm 194$ & $1899 \pm 319$ \\
\hline & MPTP & $2589 \pm 602$ & $714 \pm 237$ & $2043 \pm 418$ \\
\hline & MPTP + nicotine & $1814 \pm 508$ & $652 \pm 252$ & $1323 \pm 296$ \\
\hline
\end{tabular}

Animals were given nicotine in the drinking water and subsequently administered MPTP, with nicotine treatment continued until the animals were killed. Nicotine-evoked dopamine release $\left(R_{\max }\right)$ was then determined in the absence (Total) and presence of $50 \mathrm{nM} \alpha$-conotoxinMII ( $\alpha 4^{*}$ nAChR component). The difference between total release and that occurring in the presence of $\alpha$-conotoxinMII was defined as the $\alpha 6^{*} \mathrm{nAChR}$ component. Each value represents the mean \pm SEM of five to seven animals. These values were used to calculate nicotine-evoked fractional $\left[{ }^{3} \mathrm{H}\right]$ dopamine release or release from residual terminals, which represents maximal evoked dopamine release $\left(R_{\max }\right)$ divided by dopamine transporter values (Table 1) as described previously (Snyder et al., 1990).

flected by a decline in the dopamine transporter (Table 1), we determined nicotine-evoked fractional $\left[{ }^{3} \mathrm{H}\right]$ dopamine release from synaptosomes prepared from striatum of unlesioned and lesioned monkeys. To measure fractional release or release from residual terminals, maximal $\mathrm{nAChR}$-evoked dopamine release $\left(R_{\max }\right)$ was divided by dopamine transporter values as described previously (Snyder et al., 1990). The results in Figure 1 show that nicotine treatment had no significant effect on fractional nicotine-evoked $\left[{ }^{3} \mathrm{H}\right]$ dopamine release in unlesioned animals. In contrast, nigrostriatal damage significantly enhanced fractional release in all striatal subregions $(p<0.05)$. Chronic nicotine treatment significantly decreased the enhanced fractional release in MPTP-lesioned compared with unlesioned monkeys in both ventral and dorsal putamen $(p<0.05)$. There were also declines in the fractional release in the caudate with nicotine administration; however, these did not reach statistical significance.

\section{Nicotine treatment has a predominant effect on $\alpha 3^{*} / \alpha 6^{*}$ nAChR-mediated fractional dopamine release in striatum} $\mathrm{nAChR}$-mediated dopamine release in the primate striatum is primarily mediated by $\alpha 3^{\star} / \alpha 6^{\star}$ and $\alpha 4^{\star}$ nAChR subtypes (McCallum et al., 2005), with the asterisks indicating the presence of other subunits in the receptor complex. To differentiate these two components of nicotine-evoked release, we used the selective $\alpha 3^{\star} / \alpha 6^{*} \mathrm{nAChR}$ antagonist $\alpha$-conotoxinMII to define $\alpha 3^{*} / \alpha 6^{*}$ $\mathrm{nAChR}$-evoked fractional release ( $\alpha$-conotoxinMII-sensitive) and $\alpha 4^{*}$ nAChR-mediated fractional release $(\alpha$-conotoxinMIIresistant). The results in Figure 2 show that there was a small decline in $\alpha 3^{\star} / \alpha 6^{*} \mathrm{nAChR}$-mediated (or $\alpha$-conotoxinMIIsensitive) fractional dopamine release with chronic nicotine treatment in some striatal regions as reported previously $(\mathrm{McCal}-$ lum et al., 2006b). Nigrostriatal damage significantly $(p<0.01)$ enhanced release in both caudate and putamen. In contrast, in lesioned monkeys treated with nicotine, a reduction was ob- 

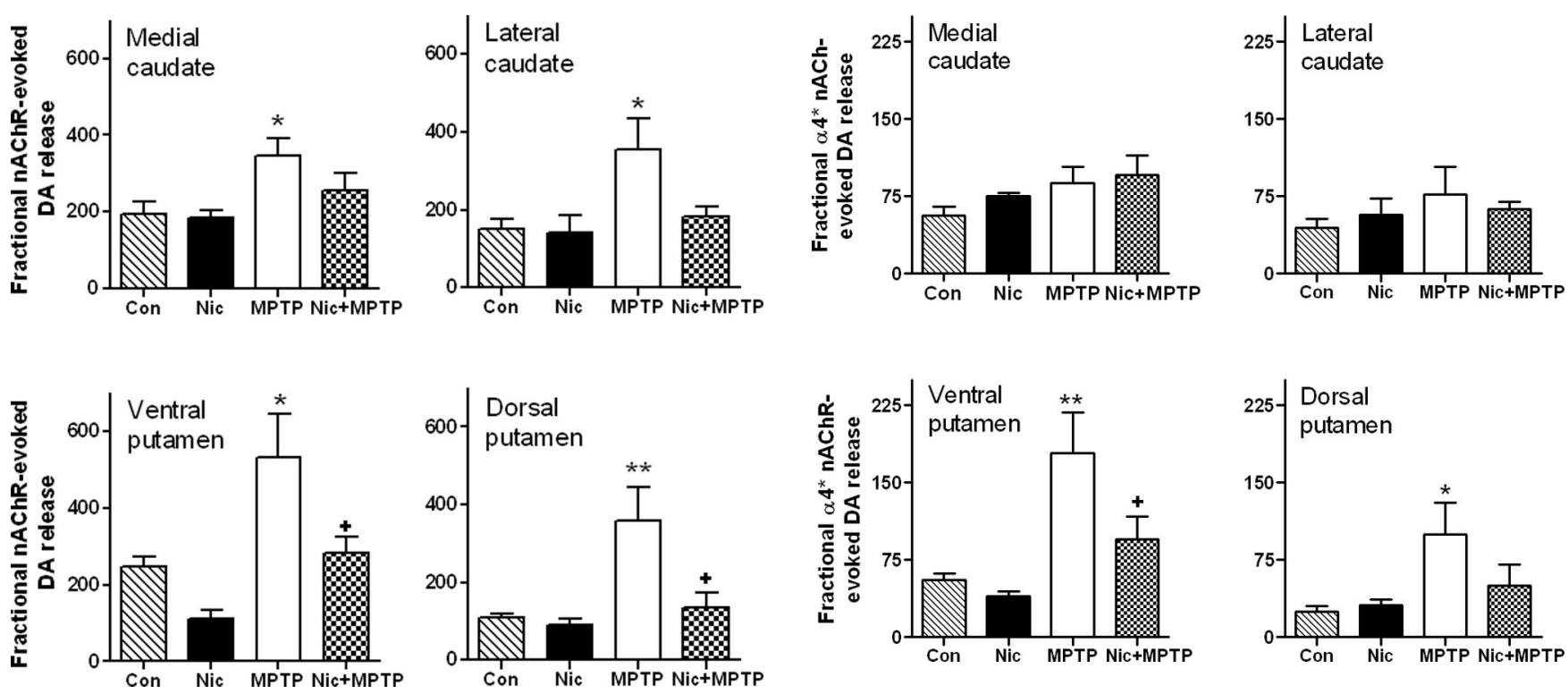

Figure 1. Chronic nicotine treatment reduces the enhanced striatal nAChR-mediated fractional $\left[{ }^{3} \mathrm{H}\right]$ dopamine release that occurs with nigrostriatal damage. Monkeys were administered chronic nicotine (Nic) and/or MPTP as described previously. Nicotine-evoked $\left[{ }^{3} \mathrm{H}\right]$ dopamine release was then determined from striatal synaptosomes. Results are expressed as the total nicotine-mediated $\left[{ }^{3} \mathrm{H}\right]$ dopamine release $\left(R_{\max } ; \mathrm{cpm} / \mathrm{mg}\right.$ tissue) divided by the dopamine transporter values ( $\mathrm{nCi} / \mathrm{mg}$ tissue). They represent the mean \pm SEM of five to seven monkeys per group. Significance of difference from the control group (Con) using Bonferroni's post hoc test, ${ }^{*} p<0.05 ;{ }^{* *} p<0.01$. Significance of difference from the MPTP-treated group, ${ }^{+} p<$ 0.05 .
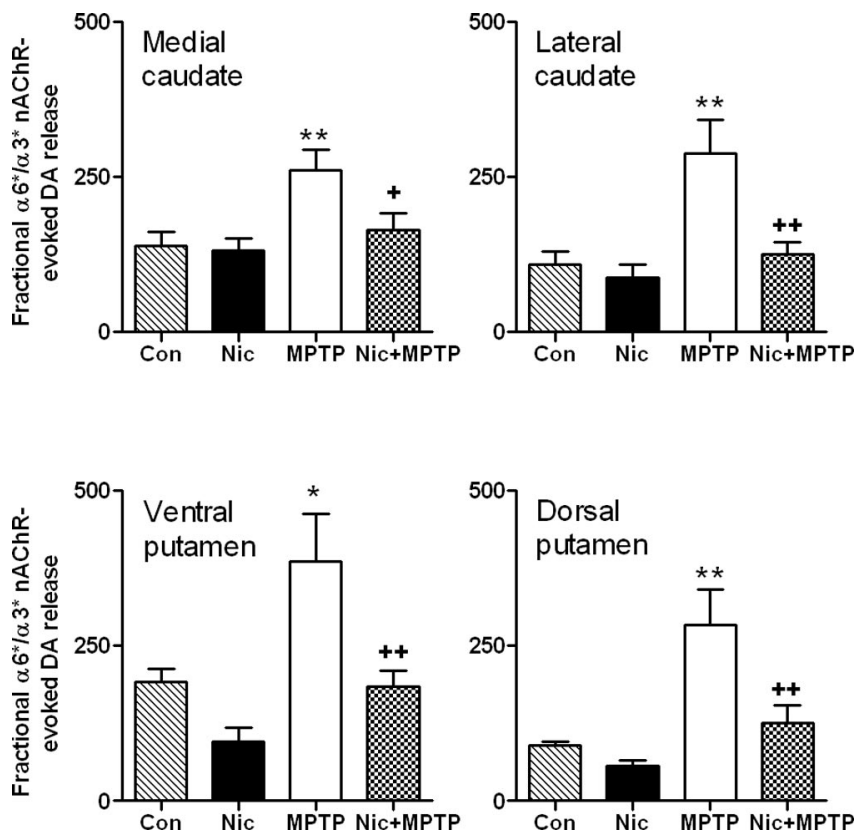

Figure 2. Chronic nicotine treatment reduces the enhanced striatal $\alpha 3^{*} / \alpha 6^{*}$ nAChRmediated fractional $\left[{ }^{3} \mathrm{H}\right]$ dopamine release that occurs with nigrostriatal damage. Monkeys were administered chronic nicotine (Nic) and/or MPTP as described previously. $\alpha 3 * / \alpha 6^{*}$ receptor-mediated $\left[{ }^{3} \mathrm{H}\right]$ dopamine release from striatal synaptosomes was then determined using $50 \mathrm{~nm} \alpha$-conotoxinMII to distinguish between $\alpha 3^{*} / \alpha 6^{*}$ nAChR-mediated ( $\alpha$ conotoxinMII-sensitive) and $\alpha 4^{*}$ nAChR-mediated ( $\alpha$-conotoxinMII-resistant) dopamine release. Results are expressed as the total nicotine-mediated $\left[{ }^{3} \mathrm{H}\right]$ dopamine release $\left(R_{\max }\right.$; $\mathrm{cpm} / \mathrm{mg}$ tissue) divided by the dopamine transporter values ( $\mathrm{nCi} / \mathrm{mg}$ tissue). They represent the mean \pm SEM of five to seven monkeys per group. Significance of difference from the control group (Con) using Bonferroni's post hoc test, ${ }^{*} p<0.05 ;{ }^{* *} p<0.01$. Significance of difference from the MPTP-treated group, ${ }^{+} p<0.05 ;^{++} p<0.01$.

Figure 3. Chronic nicotine treatment reduces the enhanced $\alpha 4^{*}$ nAChR-mediated fractional $\left[{ }^{3} \mathrm{H}\right]$ dopamine release only in putamen of monkeys with nigrostriatal damage. Monkeys were administered chronic nicotine (Nic) and/or MPTP as described. $\alpha 4^{*}$ receptor-mediated $\left[{ }^{3} \mathrm{H}\right] \mathrm{do}$ pamine release from striatal synaptosomes was then determined using $50 \mathrm{~nm} \alpha$-conotoxinMII to distinguish between $\alpha 4^{*}$ nAChR-mediated ( $\alpha$-conotoxinMII-resistant) and $\alpha 3^{*} / \alpha 6^{*}$ nAChR-mediated ( $\alpha$-conotoxinMII-sensitive) dopamine release. Results are expressed as the total nicotine-mediated [ $\left.{ }^{3} \mathrm{H}\right]$ dopamine release $\left(R_{\max } ; \mathrm{cpm} / \mathrm{mg}\right.$ tissue) divided by the dopamine transporter values ( $\mathrm{nCi} / \mathrm{mg}$ tissue). They represent the mean \pm SEM of five to seven monkeys per group. Significance of difference from the control group (Con) using Bonferroni's post hoc test, ${ }^{*} p<0.05 ;{ }^{* *} p<0.01$. Significance of difference from the MPTP-treated group, ${ }^{+} p<$ 0.05

served in striatal $\alpha$-conotoxinMII-sensitive nicotine-evoked dopamine release compared with lesioned animals not treated with nicotine $(p<0.01)$.

$\alpha 4^{\star}$ nAChR-mediated ( $\alpha$-conotoxinMII-resistant) $\left[{ }^{3} \mathrm{H}\right]$ dopamine release was also analyzed in the same treatment groups (Fig. 3). There was no change in fractional $\alpha 4^{\star}$ receptor-evoked dopamine release in animals treated only with nicotine. A significant increase was obtained in both ventral and dorsal putamen with nigrostriatal damage. This enhanced response was reduced with nicotine treatment, although significantly $(p<0.05)$ only in the ventral putamen. This contrasts with the lack of change in $\alpha 4^{*}$ receptor-stimulated fractional release in the caudate under any condition.

Nicotine treatment normalizes MPTP-induced increases in fractional $\mathrm{K}^{+}$-evoked striatal dopamine release

Experiments were subsequently done to determine whether the effect of chronic nicotine treatment was selective for nicotineevoked $\left[{ }^{3} \mathrm{H}\right]$ dopamine release or whether there were also compensatory changes in fractional $\mathrm{K}^{+}$-evoked release. The results in Figure 4 show that nicotine treatment alone had no effect on fractional $\mathrm{K}^{+}$-evoked $\left[{ }^{3} \mathrm{H}\right]$ dopamine release in unlesioned animals. In contrast, nigrostriatal damage significantly enhanced release in the ventral and dorsal putamen $(p<0.05)$, but not caudate. This enhanced release in putamen was no longer observed in MPTP-lesioned monkeys receiving chronic oral nicotine.

\section{Nicotine treatment normalizes MPTP-induced increases in} striatal dopamine turnover

Numerous studies have shown that there are significant changes in dopamine and metabolite levels after nigrostriatal damage in 


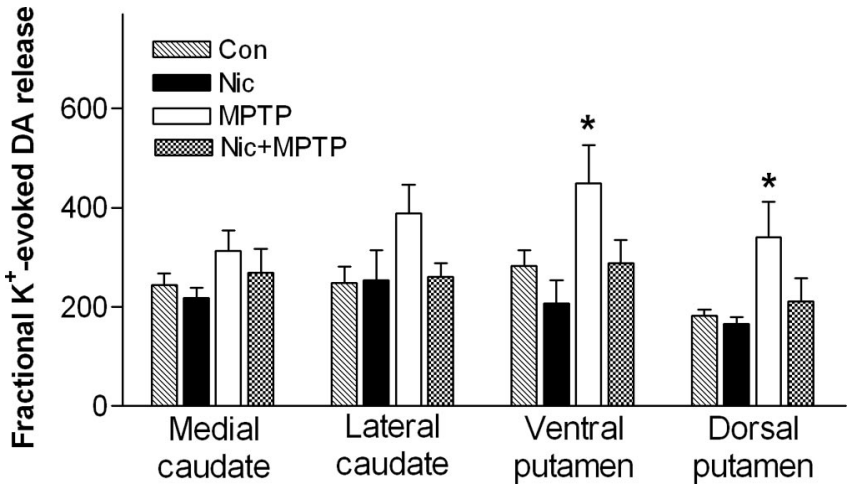

Figure 4. Long-term nicotine treatment reduces the enhanced $\mathrm{K}^{+}$-evoked fractional $\left[{ }^{3} \mathrm{H}\right]$ dopamine release from monkey striatal regions after nigrostriatal damage. Monkeys were chronically treated with nicotine (Nic) and/or MPTP. $\left[{ }^{3} \mathrm{H}\right]$ Dopamine release was then evoked from striatal synaptosomes using $20 \mathrm{~mm} \mathrm{~K}^{+}$. Results are expressed as the $\mathrm{K}^{+}$-mediated $\left[{ }^{3} \mathrm{H}\right]$ dopamine release $(\mathrm{cpm} / \mathrm{mg}$ tissue) divided by the dopamine transporter values $(\mathrm{nCi} / \mathrm{mg}$ tissue). They represent the mean \pm SEM of five to seven monkeys per group. Significance of difference from the respective control group (Con) in the same striatal region using Bonferroni's post hoc test, ${ }^{*} p<0.05$.

Table 3. Effect of nicotine and/or MPTP treatments on striatal dopamine and metabolite levels

\begin{tabular}{lllll}
\hline & & \multicolumn{3}{l}{ Concentration (ng/mg protein) } \\
\cline { 3 - 5 } Striatal region & Treatment group & Dopamine & DOPAC & HVA \\
\hline Medial caudate & Control & $89.64 \pm 2.84$ & $17.67 \pm 3.05$ & $46.05 \pm 3.71$ \\
& Nicotine & $102.6 \pm 7.57$ & $11.15 \pm 2.43$ & $41.06 \pm 3.56$ \\
& MPTP & $29.12 \pm 5.25^{*}$ & $7.06 \pm 0.69^{*}$ & $22.65 \pm 2.94^{*}$ \\
& MPTP + nicotine & $54.17 \pm 8.13^{*}$ & $6.38 \pm 0.92^{*}$ & $28.06 \pm 4.40^{*}$ \\
Lateral caudate & Control & $97.81 \pm 6.04$ & $14.87 \pm 3.70$ & $47.45 \pm 3.62$ \\
& Nicotine & $99.57 \pm 9.29$ & $9.77 \pm 1.73$ & $37.01 \pm 3.79$ \\
& MPTP & $12.49 \pm 5.47^{*}$ & $2.44 \pm 0.70^{*}$ & $23.43 \pm 4.53^{*}$ \\
& MPTP + nicotine & $26.89 \pm 12.01^{*}$ & $3.70 \pm 0.74^{*}$ & $27.09 \pm 6.34^{*}$ \\
Ventral putamen & Control & $115.8 \pm 11.95$ & $15.31 \pm 3.40$ & $71.60 \pm 5.54$ \\
& Nicotine & $127.4 \pm 13.24$ & $12.09 \pm 2.27$ & $63.44 \pm 5.28$ \\
& MPTP & $14.92 \pm 4.97^{*}$ & $2.58 \pm 0.61^{*}$ & $36.09 \pm 5.04^{*}$ \\
& MPTP + nicotine & $42.27 \pm 7.10^{*}$ & $6.73 \pm 1.77^{*}$ & $42.49 \pm 3.42^{*}$ \\
& & & & \\
Dorsal putamen & Control & $109.9 \pm 12.61$ & $10.87 \pm 1.18$ & $60.16 \pm 3.57$ \\
& Nicotine & $127.5 \pm 11.33$ & $10.02 \pm 1.66$ & $53.62 \pm 5.59$ \\
& MPTP & $2.46 \pm 0.57^{*}$ & $0.97 \pm 0.16^{*}$ & $23.11 \pm 3.44^{*}$ \\
& MPTP + nicotine & $9.82 \pm 4.46^{*}$ & $2.16 \pm 0.71^{*}$ & $30.53 \pm 3.14^{*}$ \\
\hline
\end{tabular}

Animals were given nicotine in the drinking water and subsequently administered MPTP, with nicotine treatment continued until the animals were killed. Brain dopamine and metabolite levels were then measured in the different striatal areas. Each value represents the mean \pm SEM of five to seven animals. The results were analyzed using a two-way ANOVA followed by Bonferroni's post hoc test. Significance of difference from control, ${ }^{*} p<0.01$.

Parkinson's disease and in animal models (Zigmond et al., 1990; Hornykiewicz, 2001). To determine the effect of chronic nicotine treatment with nigrostriatal damage, dopamine, DOPAC, and HVA were determined in monkey striatum (Table 3). The results show that these measures were reduced with nigrostriatal damage in every region of striatum $(p<0.01)$. Nicotine treatment had no effect on dopamine levels in unlesioned animals, although there was a significant main effect of nicotine $(p<0.01)$ in lesioned animals as shown previously (Quik et al., 2005b).

The ratio of dopamine levels to those of the dopamine metabolites DOPAC and HVA (dopamine/DOPAC plus HVA), or dopamine turnover, was subsequently calculated (Fig. 5) as a measure of dopamine clearance by remaining dopaminergic neurons (Zigmond et al., 1990; Hornykiewicz, 2001). An increase was observed in dopamine turnover in all subregions of striatum
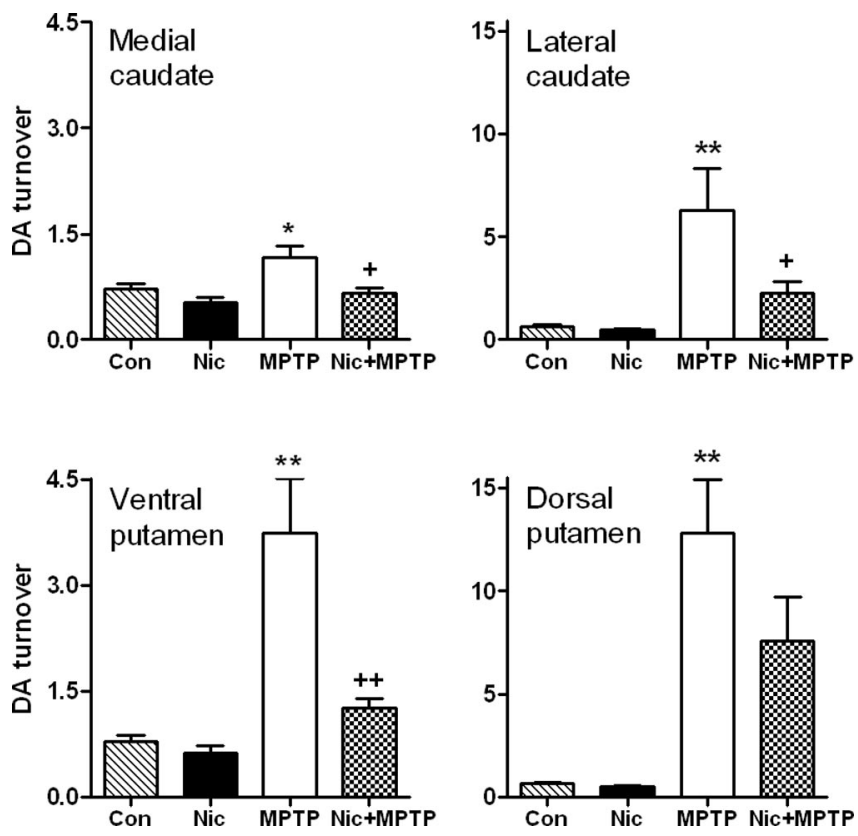

Figure 5. Chronic nicotine treatment reduces the enhanced dopamine turnover observed in monkey striatum after nigrostriatal damage. Monkeys were administered chronic nicotine (Nic) and/or MPTP as described previously. Dopamine, DOPAC, and HVA were then measured in the different striatal regions, and dopamine turnover (dopamine/DOPAC plus HVA) was quantitated. Values represent the mean \pm SEM of five to seven monkeys per group. Significance of difference from the control group (Con) using Bonferroni's post hoc test, ${ }^{*} p<0.05$; ${ }^{* *} p<0.01$. Significance of difference from the MPTP-treated group, ${ }^{+} p<0.05 ;{ }^{+} p<0.01$.

from lesioned monkeys, with the greatest increases $(p<0.01)$ in the lateral caudate and dorsal putamen, that is, the regions with the greatest dopaminergic loss. Dopamine turnover rates in animals treated with nicotine and MPTP were significantly lower than in animals treated only with MPTP in medial caudate $(p<$ $0.05)$, lateral caudate $(p<0.05)$, and ventral putamen $(p<$ $0.01)$, although not dorsal putamen.

\section{Chronic nicotine treatment reduces the threshold for corticostriatal LTD induction in unlesioned and MPTP- lesioned monkeys}

Corticostriatal slices for electrophysiological recording were prepared from brain sections at level A12-A13. Cortical stimulationevoked field potentials (EFPs) were evoked by bipolar stimulation of projection fibers in ACSF containing $\mathrm{Mg}^{2+}$. Initial studies to establish control parameters for in vitro electrophysiological recording in monkey slices showed that the amplitude of EFPs was dependent on stimulus strength (our unpublished observations). Subsequent tetanus stimulation $(100 \mathrm{~Hz} ; 100 \mu \mathrm{s} ; 14 \mathrm{~V}$; 20-900 pulses) of the corticostriatal pathway induced a LTD, which is the predominant change in plasticity observed using physiological concentrations of $\mathrm{Mg}^{2+}$ (Centonze et al., 2001; Pisani et al., 2005). Corticostriatal LTD recordings were obtained from the majority ( 7 of 10) of control monkeys, with representative data from one monkey depicted in Figure 6A. The LTD induction threshold was defined as the minimum number of HFS pulses necessary to generate a significant long-term (>20 min) decrease in EFP amplitude. In contrast, tetanus stimulation failed to induce LTD in slices from any MPTP-lesioned monkey ( 0 of 3 ) (Fig. 6B), consistent with studies in rodents (Calabresi et al., 1992a,b; Centonze et al., 1999, 2001; Chen et al., 2006). Stimulation of the corticostriatal pathway in slices from animals chronically treated with nicotine (Fig. 6 C) also resulted in LTD in three 
of the four treated animals. In nicotinetreated MPTP-lesioned animals, a robust LTD was observed (Fig. 6D) in four of the five.

The combined results from the monkeys in each group exhibiting LTD is depicted in Figure 7. The results show that chronic nicotine treatment significantly reduced the threshold for LTD induction in both unlesioned and MPTP-lesioned monkeys. These data suggest that chronic oral nicotine treatment enhances synaptic plasticity in both unlesioned and MPTPlesioned monkeys.

\section{Discussion}

The present experiments are the first to show that chronic oral nicotine normalizes aberrant striatal function that occurs as a consequence of nigrostriatal damage. To approach this, we evaluated several measures of striatal activity. These include dopamine release, dopamine turnover, and synaptic plasticity, with the latter defined by changes in LTD. We first determined nAChR-mediated dopamine release (Wonnacott, 1997), a measure directly linked to nicotine treatment. Chronic nicotine dosing normalized the lesion-induced increase in nicotineevoked release from residual dopamine terminals in monkey striatum. Unexpectedly, nicotine treatment also reduced $\mathrm{K}^{+}$evoked fractional dopamine release and dopamine turnover, which were both elevated as a result of nigrostriatal damage (Zigmond et al., 1984, 1990; Zigmond, 1997; Hornykiewicz, 1998, 2001; McCallum et al., 2006a). These combined data indicate that nicotine treatment not only restores functional measures directly associated with $\mathrm{nAChR}$ stimulation but also results in a generalized return of striatal function to normal after chronic nigrostriatal damage.

We also investigated the effect of nicotine treatment on striatal plasticity in both unlesioned and lesioned animals because changes in synaptic strength are implicated in motor function (Pisani et al., 2005). Repetitive stimulation of the corticostriatal pathway can induce long-term potentiation and LTD, with the direction of the change in plasticity dependent on the level of membrane depolarization and the select neuronal systems activated (Pisani et al., 2005). Under the present experimental conditions (ACSF containing $\mathrm{Mg}^{2+}$ ), the synaptic change was LTD as previously observed in the rodent corticostriatal pathway (Calabresi et al., 1992a,b; Centonze et al., 1999, 2001; Chen et al., 2006). Interestingly, the synaptic plasticity lost with nigrostriatal damage was preserved in lesioned animals with chronic nicotine treatment, that is, LTD was restored. Because synaptic plasticity in test $\left({ }^{*} p<0.05\right)$.
A. Control

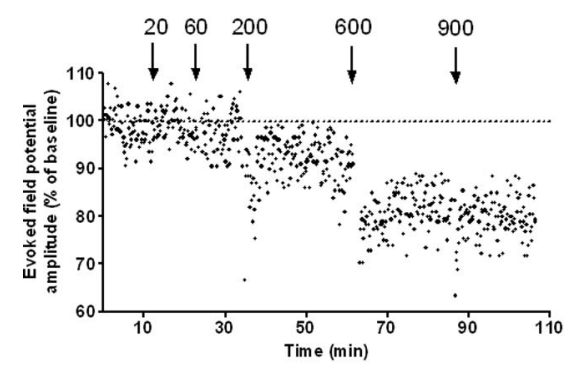

B. MPTP-treated

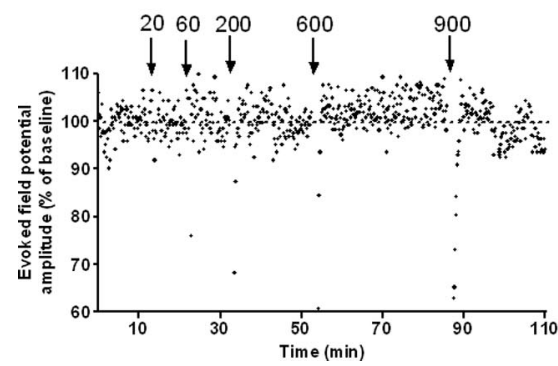

C. Nicotine-treated

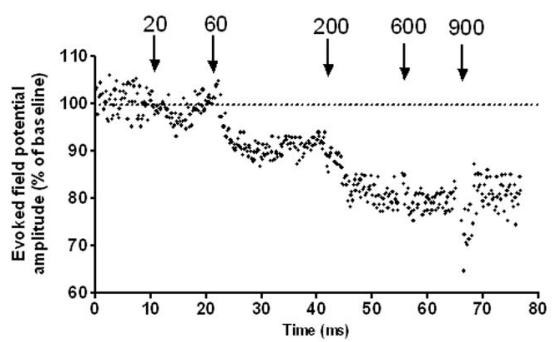

D. Nicotine- and MPTP-treated

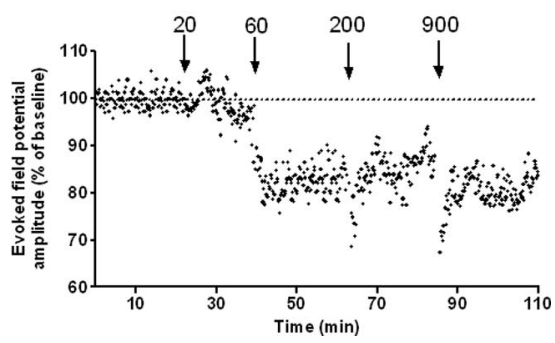

Figure 6. Effect of chronic nicotine treatment and nigrostriatal damage on the induction of corticostriatal LTD. Monkeys were chronically treated with nicotine in the drinking water and subsequently lesioned with MPTP. Corticostriatal slices were prepared from level A13-A12 as described in Materials and Methods. They were stimulated with a varying number (20-900) of HFS pulses $(100 \mathrm{~Hz} ; 100 \mu \mathrm{s} ; 14 \mathrm{~V})$ and cortical stimulation EFPs were recorded. $\boldsymbol{A}$, Evoked field potential amplitudes (expressed as a percentage of baseline) every 10 s in a slice preparation from an unlesioned monkey shows that HFS at 600 pulses induced LTD. $B$, Nicotine treatment appears to reduce the threshold for corticostriatal LTD induction to 60 pulses. C, LTD was not observed with HFS (up to 900 pulses) after nigrostriatal damage. D, However, LTD was observed in the MPTP-lesioned group with chronic nicotine treatment. The results in $\boldsymbol{A}-\boldsymbol{D}$ are from a representative animal in each group.

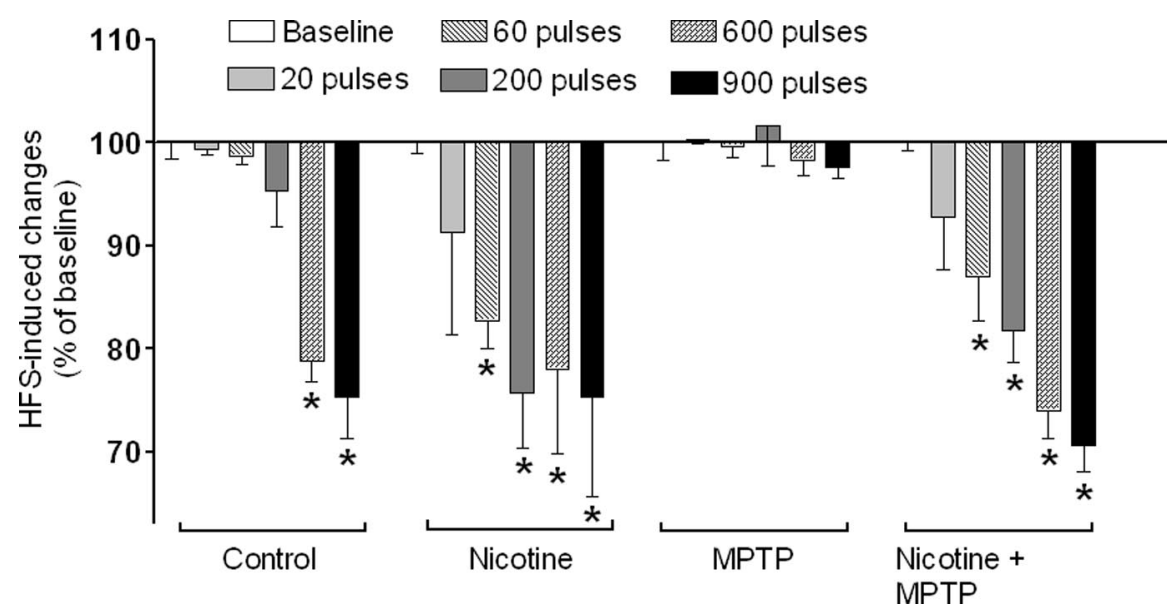

Figure 7. Chronic nicotine treatment reduces the threshold for LTD induction in unlesioned and MPTP-lesioned monkeys. The threshold of LTD induction was defined as the minimal number of HFS pulses required to generate a significant long-term $(>20$ $\mathrm{min}$ ) decrease in EFP amplitude compared with baseline. Shown are the combined results from three to four monkeys per group, with each bar representing the mean \pm SEM of amplitude of EFPs after HFS (expressed as a percentage of baseline). Significance of difference from baseline was determined using one-way ANOVA followed by a Newman-Keuls post hoc multiple comparison

basal ganglia motor circuits has been proposed as a neuronal mechanism underlying motor learning and memory (Pisani et al., 2005), these data support the idea that chronic nicotine administration helps maintain/restore normal nigrostriatal function.

In the current study, nicotine was administered before and during the development of nigrostriatal damage. This regimen was selected because our intent was to determine whether the 
nicotine in tobacco might account, at least in part, for the decreased incidence of Parkinson's disease with smoking. With the current nicotine-dosing schedule, striatal function may have normalized because nicotine improved function after injury and/or reduced the MPTP-induced nigrostriatal degeneration. This damage was most likely attributable to the neurotoxic effects of MPTP, but may also have occurred because of compensatory increases in dopamine turnover and fractional dopamine release after nigrostriatal damage (Zigmond et al., 1990; Zigmond, 1997; Elsworth et al., 2000; McCallum et al., 2006a). Elevated dopamine levels have been shown to increase production of reactive oxygen species such as peroxides, superoxides, and hydroxyl radicals and dopamine quinones in residual dopamine terminals (Halliwell, 1992; Hastings et al., 1996; Blum et al., 2001). These cytotoxic products may augment the existing nigrostriatal damage (Rosenberg, 1988; Masserano et al., 1996; McLaughlin et al., 1998; Berman and Hastings, 1999).

Nicotine may exert a protective action against toxicity in several ways. It may diminish elevated dopaminergic function through an interaction at nAChRs. Two primary subtypes in the primate striatum include $\alpha 3 / \alpha 6^{*}$ and $\alpha 4^{*} \mathrm{nAChRs,} \mathrm{with} \mathrm{the} \mathrm{as-}$ terisks indicating the presence of additional subunits in the receptor complex (Quik et al., 2005a). These form pentameric heteromeric receptors that mediate dopamine release in the striatum (Gotti and Clementi, 2004), with $\sim 70 \%$ release evoked by stimulation of $\alpha 3^{\star} / \alpha 6^{*} \mathrm{nAChRs}$ and the remainder (30\%) by $\alpha 4^{*}$ receptors (McCallum et al., 2005). Chronic nicotine administration decreases $\alpha 3^{\star} / \alpha 6^{*} \mathrm{nAChRs}$ and is well known to desensitize $\alpha 4^{\star}$ subtypes, both of which may result in alterations in neuronal transduction mechanisms (Wonnacott, 1997; Giniatullin et al., 2005; Lai et al., 2005; McCallum et al., 2006b). Changes in intracellular calcium probably represent an important initial event because nAChRs flux calcium and nAChR-evoked function is calcium dependent (O'Neill et al., 2002; Dajas-Bailador and Wonnacott, 2004; Quik, 2004; Wonnacott et al., 2005). Diverse downstream pathways and processes, such as phosphorylation, may be activated to lead to alterations in caspases, kinases, CREB (cAMP response element-binding protein), apoptotic signaling, the nitric oxide/cGMP pathway, and others (Fedele et al., 1998; Garrido et al., 2001; Brunzell et al., 2003; Mai et al., 2003; Jin et al., 2004).

Activation of these signaling mechanisms may subsequently lead to neuroprotection through a variety of mechanisms including changes in synaptic plasticity. For instance, in the present studies, we observed that chronic nicotine treatment facilitated corticostriatal synaptic plasticity or LTD, a function dependent on nAChR-evoked dopamine release (Partridge et al., 2002). The glutamatergic corticostriatal pathway is the major excitatory input to the basal ganglia (DeLong, 1990; Partridge et al., 2002; Kolomiets et al., 2003). Chronic nicotine treatment may attenuate neuronal damage by reducing glutamatergic excitoxicity in the striatum through an enhanced LTD.

Nicotine may also enhance/restore striatal dopaminergic nerve terminal integrity and function through a trophic action. nAChR activation is well known to stimulate neuronal growth (Chan and Quik, 1993; Zheng et al., 1994; Erskine and McCaig, 1995; Owen and Bird, 1995; Coronas et al., 2000; Pugh and Margiotta, 2000). Although the mechanisms are unclear, nicotine may stimulate trophic factors such as basic fibroblast growth factor, which are elevated in rodents after chronic nicotine treatment (Belluardo et al., 2000).

In addition, nicotine may act through receptor-independent mechanisms. These include a direct antioxidant effect possibly through lipid peroxidation and/or by scavenging reactive oxygen species such as superoxides (Soto-Otero et al., 2002; Cormier et al., 2003). Nicotine also appears to compete with NADH to attenuate mitochondrial respiratory control (Cormier et al., 2003), and to reduce mitochondrial swelling and cytochrome $c$ release from mitochondria in the presence of $\mathrm{nAChR}$ blockers (Xie et al., 2005). In addition, liver metabolizing enzymes such as cytochrome P450 are induced by nicotine (Tyndale, 2003; Hukkanen et al., 2005).

It is unlikely that nicotine had a direct effect on MPTP biodisposition, because previous studies had shown that nicotine only affected dopaminergic measures in the striatum and not dopaminergic cell number in the substantia nigra (Quik et al., 2005b). As well, the activity of monoamine oxidase, the enzyme responsible for the conversion of MPTP to the active metabolite MPP ${ }^{+}$, was not different in animals treated with or without nicotine (our unpublished observation).

The almost complete restoration of striatal function, that is, fractional dopamine release, dopamine turnover, and LTD, after nicotine treatment was unexpected when compared with the much smaller reversal ( 20\%) in striatal dopaminergic markers (Quik et al., 2005b). Tyrosine hydroxylase, the dopamine transporter, vesicular monoamine transporter and dopamine levels were still reduced $>50 \%$ after nigrostriatal damage in nicotinetreated monkeys, although some functional measures were almost normal. This discrepancy may relate to multiple adaptive mechanisms that arise after nigrostriatal damage. These include other presynaptic dopaminergic changes (Zigmond et al., 1990; Zigmond, 1997; Hornykiewicz, 2001), as well as alterations in postsynaptic mechanisms such as dopamine receptor supersensitivity and in tachykinin, enkephalinergic, GABAergic, and cholinergic function (Lee et al., 1978; Todd et al., 1996; Zigmond, 1997; Bezard et al., 2001, 2003; Meissner et al., 2003).

The primate striatum is anatomically diverse and receives differential dopaminergic inputs from discrete regions in the substantia nigra to result in ventromedial to dorsolateral innervation gradients in the striatum. These gradients are associated with distinct patterns of striatal degeneration with nigrostriatal damage, with more severe dopaminergic losses in dorsolateral compared with ventromedial regions and greater declines in the putamen than caudate in animal models and Parkinson's disease (Parent et al., 1983; Hirsch et al., 1988; Kemel et al., 1989; Gibb et al., 1990; Graybiel et al., 1990; Fearnley and Lees, 1991; Parent and Lavoie, 1993). The present data also exhibit ventromedial to dorsolateral gradients in MPTP-lesioned animals with a more pronounced neurodegeneration in the putamen than caudate. Moreover, the functional restoration with nicotine treatment parallels these morphological gradients.

The finding that nicotine administration ameliorates function in monkeys with nigrostriatal degeneration raises the question whether it may be of therapeutic benefit. To date, administration of the nicotine patch and/or gum has yielded conflicting results, with some studies reporting small improvements in motor and cognitive deficits and others no effect or a decline (Ishikawa and Miyatake, 1993; Fagerstrom et al., 1994; Ebersbach et al., 1999; Kelton et al., 2000; Vieregge et al., 2001; Lemay et al., 2004). Drawbacks of these studies include the limited number of subjects and very short duration (2-4 weeks). The current experimental design would suggest that longer treatment periods with nicotine are required. The use of nicotine for Parkinson's disease therapy therefore requires further study.

In summary, the present results show that chronic nicotine treatment tends to normalize lesion-induced overactivity of the 
nigrostriatal pathway, with an attenuation of the enhanced striatal dopamine turnover and evoked dopamine release. In addition, nicotine treatment preserves synaptic plasticity that is lost with nigrostriatal damage. These results suggest that long-term nicotine administration has potential as a treatment strategy to either protect against or restore dopaminergic terminal function in Parkinson's disease, a chronic disorder with progressive neurodegeneration.

\section{References}

Allam MF, Campbell MJ, Hofman A, Del Castillo AS, Fernandez-Crehuet Navajas R (2004) Smoking and Parkinson's disease: systematic review of prospective studies. Mov Disord 19:614-621.

Belluardo N, Mudo G, Blum M, Fuxe K (2000) Central nicotinic receptors, neurotrophic factors and neuroprotection. Behav Brain Res 113:21-34.

Berman SB, Hastings TG (1999) Dopamine oxidation alters mitochondrial respiration and induces permeability transition in brain mitochondria: implications for Parkinson's disease. J Neurochem 73:1127-1137.

Bezard E, Dovero S, Prunier C, Ravenscroft P, Chalon S, Guilloteau D, Crossman AR, Bioulac B, Brotchie JM, Gross CE (2001) Relationship between the appearance of symptoms and the level of nigrostriatal degeneration in a progressive 1-methyl-4-phenyl-1,2,3,6-tetrahydropyridine-lesioned macaque model of Parkinson's disease. J Neurosci 21:6853-6861.

Bezard E, Gross CE, Brotchie JM (2003) Presymptomatic compensation in Parkinson's disease is not dopamine-mediated. Trends Neurosci 26:215-221.

Blum D, Torch S, Lambeng N, Nissou M, Benabid AL, Sadoul R, Verna JM (2001) Molecular pathways involved in the neurotoxicity of 6-OHDA, dopamine and MPTP: contribution to the apoptotic theory in Parkinson's disease. Prog Neurobiol 65:135-172.

Brunzell DH, Russell DS, Picciotto MR (2003) In vivo nicotine treatment regulates mesocorticolimbic CREB and ERK signaling in C57BL/6J mice. J Neurochem 84:1431-1441.

Buisson B, Bertrand D (2002) Nicotine addiction: the possible role of functional upregulation. Trends Pharmacol Sci 23:130-136.

Calabresi P, Maj R, Mercuri NB, Bernardi G (1992a) Coactivation of D1 and D2 dopamine receptors is required for long-term synaptic depression in the striatum. Neurosci Lett 142:95-99.

Calabresi P, Maj R, Pisani A, Mercuri NB, Bernardi G (1992b) Long-term synaptic depression in the striatum: physiological and pharmacological characterization. J Neurosci 12:4224-4233.

Centonze D, Gubellini P, Picconi B, Calabresi P, Giacomini P, Bernardi G (1999) Unilateral dopamine denervation blocks corticostriatal LTP. J Neurophysiol 82:3575-3579.

Centonze D, Picconi B, Gubellini P, Bernardi G, Calabresi P (2001) Dopaminergic control of synaptic plasticity in the dorsal striatum. Eur J Neurosci 13:1071-1077.

Chan J, Quik M (1993) A role for the nicotinic $\alpha$-bungarotoxin receptor in neurite outgrowth in PC12 cells. Neuroscience 56:441-451.

Chen L, Perez X, Xie X, Langston JW, Quik M (2005) Exogenous dopamineinduced abnormal synaptic plasticity in basal ganglia motor circuits in a rat model of dyskinesia. Soc Neurosci Abstr 31:330.12.

Cormier A, Morin C, Zini R, Tillement JP, Lagrue G (2003) Nicotine protects rat brain mitochondria against experimental injuries. Neuropharmacology 44:642-652.

Coronas V, Durand M, Chabot JG, Jourdan F, Quirion R (2000) Acetylcholine induces neuritic outgrowth in rat primary olfactory bulb cultures. Neuroscience 98:213-219.

Costa G, Abin-Carriquiry JA, Dajas F (2001) Nicotine prevents striatal dopamine loss produced by 6-hydroxydopamine lesion in the substantia nigra. Brain Res 888:336-342.

Dajas-Bailador F, Wonnacott S (2004) Nicotinic acetylcholine receptors and the regulation of neuronal signalling. Trends Pharmacol Sci 25:317-324.

DeLong MR (1990) Primate models of movement disorders of basal ganglia origin. Trends Neurosci 13:281-285.

Ebersbach G, Stock M, Muller J, Wenning G, Wissel J, Poewe W (1999) Worsening of motor performance in patients with Parkinson's disease following transdermal nicotine administration. Mov Disord 14:1011-1013.

Elsworth JD, Taylor JR, Sladek Jr JR, Collier TJ, Redmond Jr DE, Roth RH
(2000) Striatal dopaminergic correlates of stable parkinsonism and degree of recovery in old-world primates one year after MPTP treatment. Neuroscience 95:399-408.

Erskine L, McCaig CD (1995) Growth cone neurotransmitter receptor activation modulates electric field-guided nerve growth. Dev Biol 171:330-339.

Fagerstrom KO, Pomerleau O, Giordani B, Stelson F (1994) Nicotine may relieve symptoms of Parkinson's disease. Psychopharmacology (Berl) 116:117-119.

Fearnley JM, Lees AJ (1991) Ageing and Parkinson's disease: substantia nigra regional selectivity. Brain 114:2283-2301.

Fedele E, Varnier G, Ansaldo MA, Raiteri M (1998) Nicotine administration stimulates the in vivo $\mathrm{N}$-methyl-D-aspartate receptor/nitric oxide/cyclic GMP pathway in rat hippocampus through glutamate release. Br J Pharmacol 125:1042-1048.

Garrido R, Mattson MP, Hennig B, Toborek M (2001) Nicotine protects against arachidonic-acid-induced caspase activation, cytochrome $c$ release and apoptosis of cultured spinal cord neurons. J Neurochem 76:1395-1403.

Gentry CL, Lukas RJ (2002) Regulation of nicotinic acetylcholine receptor numbers and function by chronic nicotine exposure. Curr Drug Targets CNS Neurol Disord 1:359-385.

Gibb WR, Fearnley JM, Lees AJ (1990) The anatomy and pigmentation of the human substantia nigra in relation to selective neuronal vulnerability. Adv Neurol 53:31-34.

Giniatullin R, Nistri A, Yakel JL (2005) Desensitization of nicotinic ACh receptors: shaping cholinergic signaling. Trends Neurosci 28:371-378.

Gotti C, Clementi F (2004) Neuronal nicotinic receptors: from structure to pathology. Prog Neurobiol 74:363-396.

Graybiel AM, Ohta K, Roffler-Tarlov S (1990) Patterns of cell and fiber vulnerability in the mesostriatal system of the mutant mouse weaver. I. Gradients and compartments. J Neurosci 10:720-733.

Hadjiconstantinou M, Hubble JP, Wemlinger TA, Neff NH (1994) Enhanced MPTP neurotoxicity after treatment with isoflurophate or cholinergic agonists. J Pharmacol Exp Ther 270:639-644.

Halliwell B (1992) Reactive oxygen species and the central nervous system. J Neurochem 59:1609-1623.

Hastings TG, Lewis DA, Zigmond MJ (1996) Role of oxidation in the neurotoxic effects of intrastriatal dopamine injections. Proc Natl Acad Sc USA 93:1956-1961.

Hirsch E, Graybiel AM, Agid YA (1988) Melanized dopaminergic neurons are differentially susceptible to degeneration in Parkinson's disease. Nature 334:345-348.

Hornykiewicz O (1998) Biochemical aspects of Parkinson's disease. Neurology $51:$ :-S9.

Hornykiewicz O (2001) Chemical neuroanatomy of the basal ganglia-normal and in Parkinson's disease. J Chem Neuroanat 22:3-12.

Hukkanen J, Jacob III P, Benowitz NL (2005) Metabolism and disposition kinetics of nicotine. Pharmacol Rev 57:79-115.

Ishikawa A, Miyatake T (1993) Effects of smoking in patients with earlyonset Parkinson's disease. J Neurol Sci 117:28-32.

Janson AM, Fuxe K, Goldstein M (1992) Differential effects of acute and chronic nicotine treatment on MPTP- (1-methyl-4-phenyl-1,2,3,6tetrahydropyridine) induced degeneration of nigrostriatal dopamine neurons in the black mouse. Clin Investig 70:232-238.

Jeyarasasingam G, Tompkins L, Quik M (2002) Stimulation of non- $\alpha 7$ nicotinic receptors partially protects dopaminergic neurons from 1-methyl4-phenylpyridinium-induced toxicity in culture. Neuroscience 109:275-285.

Jin Z, Gao F, Flagg T, Deng X (2004) Nicotine induces multi-site phosphorylation of Bad in association with suppression of apoptosis. J Biol Chem 279:23837-23844.

Kelton MC, Kahn HJ, Conrath CL, Newhouse PA (2000) The effects of nicotine on Parkinson's disease. Brain Cogn 43:274-282.

Kemel ML, Desban M, Glowinski J, Gauchy C (1989) Distinct presynaptic control of dopamine release in striosomal and matrix areas of the cat caudate nucleus. Proc Natl Acad Sci USA 86:9006-9010.

Kolomiets BP, Deniau JM, Glowinski J, Thierry AM (2003) Basal ganglia and processing of cortical information: functional interactions between trans-striatal and trans-subthalamic circuits in the substantia nigra pars reticulata. Neuroscience 117:931-938.

Lai A, Parameswaran N, Khwaja M, Whiteaker P, Lindstrom JM, Fan H, 
McIntosh JM, Grady SR, Quik M (2005) Long-term nicotine treatment decreases striatal $\alpha 6^{*}$ nicotinic acetylcholine receptor sites and function in mice. Mol Pharmacol 67:1639-1647.

Lee T, Seeman P, Rajput A, Farley IJ, Hornykiewicz O (1978) Receptor basis for dopaminergic supersensitivity in Parkinson's disease. Nature 273:59-61.

Lemay S, Chouinard S, Blanchet P, Masson H, Soland V, Beuter A, Bedard MA (2004) Lack of efficacy of a nicotine transdermal treatment on motor and cognitive deficits in Parkinson's disease. Prog Neuropsychopharmacol Biol Psychiatry 28:31-39.

Mai H, May WS, Gao F, Jin Z, Deng X (2003) A functional role for nicotine in $\mathrm{Bcl} 2$ phosphorylation and suppression of apoptosis. J Biol Chem 278:1886-1891.

Masserano JM, Gong L, Kulaga H, Baker I, Wyatt RJ (1996) Dopamine induces apoptotic cell death of a catecholaminergic cell line derived from the central nervous system. Mol Pharmacol 50:1309-1315.

McCallum SE, Parameswaran N, Bordia T, McIntosh JM, Grady SR, Quik M (2005) Decrease in $\alpha 3^{*} / \alpha 6^{*}$ nicotinic receptors but not nicotine-evoked dopamine release in monkey brain after nigrostriatal damage. Mol Pharmacol 68:737-746.

McCallum SE, Parameswaran N, Perez XA, Bao S, McIntosh JM, Grady SR, Quik M (2006a) Compensation in pre-synaptic dopaminergic function following nigrostriatal damage in primates. J Neurochem 96:960-972.

McCallum SE, Parameswaran N, Bordia T, Fan H, Tyndale RF, Langston JW, McIntosh JM, Quik M (2006b) Increases in $\alpha 4^{\star}$ but not $\alpha 3^{\star} / \alpha 6^{*}$ nicotinic receptor sites and function in the primate striatum following chronic oral nicotine treatment. J Neurochem 96:1028-1041.

McLaughlin BA, Nelson D, Erecinska M, Chesselet MF (1998) Toxicity of dopamine to striatal neurons in vitro and potentiation of cell death by a mitochondrial inhibitor. J Neurochem 70:2406-2415.

Meissner W, Dovero S, Bioulac B, Gross CE, Bezard E (2003) Compensatory regulation of striatal neuropeptide gene expression occurs before changes in metabolic activity of basal ganglia nuclei. Neurobiol Dis 13:46-54.

Morens DM, Grandinetti A, Reed D, White LR, Ross GW (1995) Cigarette smoking and protection from Parkinson's disease: false association or etiologic clue? Neurology 45:1041-1051.

Olanow CW (2004) The scientific basis for the current treatment of Parkinson's disease. Annu Rev Med 55:41-60.

O’Neill MJ, Murray TK, Lakics V, Visanji NP, Duty S (2002) The role of neuronal nicotinic acetylcholine receptors in acute and chronic neurodegeneration. Curr Drug Target CNS Neurol Disord 1:399-411.

Owen A, Bird M (1995) Acetylcholine as a regulator of neurite outgrowth and motility in cultured embryonic mouse spinal cord. NeuroReport 6:2269-2272.

Papke RL, Meyer EM, Lavieri S, Bollampally SR, Papke TA, Horenstein NA, Itoh Y, Porter Papke JK (2004) Effects at a distance in $\alpha 7 \mathrm{nAChR}$ selective agonists: benzylidene substitutions that regulate potency and efficacy. Neuropharmacology 46:1023-1038.

Parain K, Hapdey C, Rousselet E, Marchand V, Dumery B, Hirsch EC (2003) Cigarette smoke and nicotine protect dopaminergic neurons against the 1-methyl-4-phenyl-1,2,3,6-tetrahydropyridine Parkinsonian toxin. Brain Res 984:224-232.

Parent A, Lavoie B (1993) The heterogeneity of the mesostriatal dopaminergic system as revealed in normal and parkinsonian monkeys. Adv Neurol 60:25-33.

Parent A, Mackey A, Smith Y, Boucher R (1983) The output organization of the substantia nigra in primate as revealed by a retrograde double labeling method. Brain Res Bull 10:529-537.

Partridge JG, Apparsundaram S, Gerhardt GA, Ronesi J, Lovinger DM (2002) Nicotinic acetylcholine receptors interact with dopamine in induction of striatal long-term depression. J Neurosci 22:2541-2549.

Pisani A, Centonze D, Bernardi G, Calabresi P (2005) Striatal synaptic plasticity: implications for motor learning and Parkinson's disease. Mov Disord 20:395-402.

Pugh PC, Margiotta JF (2000) Nicotinic acetylcholine receptor agonists promote survival and reduce apoptosis of chick ciliary ganglion neurons. Mol Cell Neurosci 15:113-122.
Quik M (2004) Smoking, nicotine and Parkinson's disease. Trends Neurosci 27:561-568.

Quik M, Di Monte DA (2001) Nicotine administration reduces striatal MPP+ levels in mice. Brain Res 917:219-224.

Quik M, Polonskaya Y, Kulak JM, McIntosh JM (2001) Vulnerability of ${ }^{125} \mathrm{I}$ - $\alpha$-conotoxin MII binding sites to nigrostriatal damage in monkey. J Neurosci 21:5494-5500.

Quik M, Vailati S, Bordia T, Kulak JM, Fan H, McIntosh JM, Clementi F, Gotti C (2005a) Subunit composition of nicotinic receptors in monkey striatum: effect of treatments with 1-methyl-4-phenyl-1,2,3,6tetrahydropyridine or L-DOPA. Mol Pharmacol 67:32-41.

Quik M, Parameswaran N, Bordia T, Bao S, Kim A, Tyndale RF, Langston JW, Di Monte DA, McCallum SE (2005b) Chronic oral nicotine treatment protects against striatal degeneration in monkey brain. Soc Neurosci Abstr 31:1006.3.

Rosenberg PA (1988) Catecholamine toxicity in cerebral cortex in dissociated cell culture. J Neurosci 8:2887-2894.

Ryan RE, Ross SA, Drago J, Loiacono RE (2001) Dose-related neuroprotective effects of chronic nicotine in 6-hydroxydopamine treated rats, and loss of neuroprotection in $\alpha 4$ nicotinic receptor subunit knockout mice. Br J Pharmacol 132:1650-1656.

Samii A, Nutt JG, Ransom BR (2004) Parkinson's disease. Lancet 363:1783-1793

Schapira AH (2004) Disease modification in Parkinson's disease. Lancet Neurol 3:362-368.

Snyder GL, Keller Jr RW, Zigmond MJ (1990) Dopamine efflux from striatal slices after intracerebral 6-hydroxydopamine: evidence for compensatory hyperactivity of residual terminals. J Pharmacol Exp Ther 253:867-876.

Soto-Otero R, Mendez-Alvarez E, Hermida-Ameijeiras A, Lopez-Real AM, Labandeira-Garcia JL (2002) Effects of (-)-nicotine and (-)-cotinine on 6-hydroxydopamine-induced oxidative stress and neurotoxicity: relevance for Parkinson's disease. Biochem Pharmacol 64:125-135.

Todd RD, Carl J, Harmon S, O’Malley KL, Perlmutter JS (1996) Dynamic changes in striatal dopamine $\mathrm{D}_{2}$ and $\mathrm{D}_{3}$ receptor protein and mRNA in response to 1-methyl-4-phenyl-1,2,3,6-tetrahydropyridine (MPTP) denervation in baboons. J Neurosci 16:7776-7782.

Togasaki DM, Hsu A, Samant M, Farzan B, DeLanney LE, Langston JW, Di Monte DA, Quik M (2005) The Webcam system: a simple, automated, computer-based video system for quantitative measurement of movement in nonhuman primates. J Neurosci Methods 145:159-166.

Tyndale RF (2003) Genetics of alcohol and tobacco use in humans. Ann Med 35:94-121.

Vieregge A, Sieberer M, Jacobs H, Hagenah JM, Vieregge P (2001) Transdermal nicotine in PD: a randomized, double-blind, placebo-controlled study. Neurology 57:1032-1035.

Wonnacott S (1997) Presynaptic nicotinic ACh receptors. Trends Neurosci 20:92-98.

Wonnacott S, Sidhpura N, Balfour DJ (2005) Nicotine: from molecular mechanisms to behaviour. Curr Opin Pharmacol 5:53-59.

Xie YX, Bezard E, Zhao BL (2005) Investigating the receptor-independent neuroprotective mechanisms of nicotine in mitochondria. J Biol Chem 280:32405-32412.

Zheng JQ, Felder M, Connor JA, Poo MM (1994) Turning of nerve growth cones induced by neurotransmitters. Nature 368:140-144.

Zhou X, Nai Q, Chen M, Dittus JD, Howard MJ, Margiotta JF (2004) Brainderived neurotrophic factor and trkB signaling in parasympathetic neurons: relevance to regulating $\alpha 7$-containing nicotinic receptors and synaptic function. J Neurosci 24:4340-4350.

Zigmond MJ (1997) Do compensatory processes underlie the preclinical phase of neurodegenerative disease? Insights from an animal model of parkinsonism. Neurobiol Dis 4:247-253.

Zigmond MJ, Acheson AL, Stachowiak MK, Stricker EM (1984) Neurochemical compensation after nigrostriatal bundle injury in an animal model of preclinical parkinsonism. Arch Neurol 41:856-861.

Zigmond MJ, Abercrombie ED, Berger TW, Grace AA, Stricker EM (1990) Compensations after lesions of central dopaminergic neurons: some clinical and basic implications. Trends Neurosci 13:290-296. 